\title{
Estructura formal, textual y oral del discurso público
}

\author{
Lluís MAS MANCHÓN \\ Universidad Pompeu Fabra \\ 1luis.mas@upf.edu
}

Recibido: 21 de enero de 2015

Aceptado: 11 de mayo de 2015

\begin{abstract}
Resumen
Existen tres competencias comunicativas muy valoradas en la sociedad de la información. Primero, la búsqueda, selección y gestión de grandes cantidades de información. Segundo, la redacción de textos claros, concisos y rigurosos. Y en tercer lugar, la exposición y defensa oral de esta información en un discurso público. Tradicionalmente, los estudios de periodismo han abordado estas competencias de forma independiente. Pero actualmente, instituciones y empresas de ámbitos diferentes demandan un perfil profesional capaz de aplicarlas ante cualquier tipo de información y con objetivos diversos. Se propone un modelo integral en tres niveles estructurales basado en teorías, conceptos y estudios específicos de periodismo, oratoria, retórica... o comunicación, en los últimos años. Este modelo puede contribuir a encauzar las investigaciones de académicos y representa una herramienta de entrenamiento para profesionales.
\end{abstract}

Palabras clave: Teoría del periodismo, Noticia, Expresión oral, Competencias Transversales, Modelo Estructural.

\section{Textual and oral structure of public discourse}

\begin{abstract}
There are three high valued competences in the information age. First, the search, selection and treatment of great amounts of information. Second, the writing of clear, concise and precise texts. And third, the exposition or oral defense of this information in a public discourse. Traditionally, journalism studies have dealt with these competences separately. However, today's, institutions and enterprises from very different spheres demand a professional profile capable of applying them to any type of information or topic and with very diverse purposes. A three-level comprehensive model is proposed based on theories, concepts and specific studies on the piece of news, the oratory, rhetoric... and the communication field, in the past years. This model may contribute to direct researchers of scholars and be a training tool for professionals.
\end{abstract}

Keywords: Journalism Theories, News, Oral Expression, Cross Competences, Structural Model.

\section{Referencia normalizada}

MAS MACHÓN, Lluís (2016): "Estructura formal, textual y oral del discurso público". Estudios sobre el Mensaje Periodístico. Vol. 22, Núm. 1 (enero-junio), págs.: 445-461. Madrid, Ediciones Complutense.

Sumario: 1. Introducción. 2. La estructura formal del discurso oral. 3. La estructura textual del discurso informativo. 4. La estructural oral del discurso informativo. 5. Modelo Estructural del Discurso Informativo. 6. Conclusiones. 7. Referencias bibliográficas.

\section{Introducción}

La comunicación hablada es una capacidad que distingue a las personas de otros seres vivos y que ha estado muy vinculada al gran desarrollo de las civilizaciones. Aunque es una de las actividades humanas más automáticas y rutinarias, la expresión oral sobre temas complejos o abstractos, ante grandes públicos y bajo condiciones de presión escénica, la convierten en una tarea de gran complejidad que sólo unos pocos poseen. De hecho, en la actualidad y cada vez más, esta competencia, junto con la de 
manejar grandes cantidades de información y la de redactar textos claros, concisos y resumidos, es clave en diferentes ámbitos laborales, sociales y culturales.

El ámbito académico que mejor ha trabajo estas competencias informativas y comunicativas es la Comunicación y los estudios de los medios (Balsebre, 1994; Huertas y Perona, 1999; Rodríguez Bravo, 2002; Rodero, 2003; Blanch y Lázaro; 2010), pues éstos presentan los mayores retos de la comunicación oral, esto es, la enunciación oral ante una cámara o micro y con audiencias de cientos de miles de personas. Otras disciplinas vinculadas a este ámbito académico, que durante años han estudiado y sistematizado estos conocimientos, son las ciencias del lenguaje, la oratoria, la retórica, la dialéctica, el periodismo, la publicidad, el doblaje, el teatro... Este artículo recoge los avances realizados por la academia en el desarrollo de teorías y técnicas de entrenamiento de los profesionales de la información, y propone un modelo teórico y práctico para la comunicación oral en público basado en tres niveles estructurales y competenciales: el formal, el textual y el oral. Apoyándose en los progresos más recientes en estos tres ámbitos, el modelo aúna las claves de: primero, la búsqueda y selección de información de toda índole, segundo, la composición y redacción sintetizada y clara de un texto virtual, y, tercero, su presentación o enunciación oral en público. Este modelo intenta institucionalizar una práctica que hasta el momento se apoya en la intuición y en teorías parciales. Pues, aunque en la actualidad existen profesionales de los medios con gran experiencia y probadas dotes para manejar grandes cantidades de información y "redactar" un texto oral mientras está siendo enunciado, la formación de profesionales en los nuevos medios y en la empresa de hoy requiere de un modelo teórico y práctico de formación integral (Mas Manchón, 2014a).

Por tanto, este modelo parte de los avances teóricos en la construcción, transmisión y efectos de la noticia como mensaje (van Dijk, 1990; Calhoun, 2002), y los aplica a otros procesos comunicativos en los que se enuncie cualquier tipo de información por parte de cualquier emisor en el marco de una empresa o institución y al servicio de unos objetivos estratégicos. Así pues, la transmisión de información se refiere aquí a la eficacia de la comunicación, es decía, el cumplimiento de unos objetivos a partir de unas intención, un género y un con texto comunicativo, mediante un discurso oral y ante un conjunto de receptores más o menos atentos, con o sin mediación tecnológica. Así, todo acto oral tiene componentes intencionales que combinan los tres grandes géneros mediáticos: la información argumentada y adecuadamente presentada, la sutil persuasión para lograr los objetivos estratégicos y el entretenimiento necesario para mantener la atención y una buena predisposición. De hecho, estos tres grandes géneros de la comunicación mediada (la información, la persuasión y la ficción o entretenimiento) se dan en diferente grado en los objetivos, el contenido y las formas de todo acto comunicativo (Mas Manchón, 2011c). Para lo que la transmisión hablada de información requiere de unas constantes estructurales en el nivel formal, textual y oral del discurso.

El artículo está organizado en tres partes fundamentales que abordan respectivamente estos tres niveles estructurales del discurso oral público, y que dan como resultado el modelo gráfico integral que los aúna. En primer lugar, la estructura formal o de edición informativa da las claves estructurales del qué y quién de toda informa- 
ción, y constituye el núcleo de relevancia que da razón de ser al discurso. En segundo lugar, esas claves formales son trasladadas a un texto oral (Tubau, 1993) mediante una estructura que disemina y dosifica la información, traducida en un vocabulario y lenguaje (tipos de palabras, estructura sintácticas, párrafos, coherencia y cohesión globales...), que la deben hacer comprensible, persuasiva y amena. Y en tercer lugar, la estructura oral no es sólo la representación vocal fidedigna de ese texto virtual, sino que como tal es capaz de vehicular los objetivos comunicativos más sofisticados y dar cabida a cualquier tipo de contenidos.

\section{La estructura formal del discurso oral}

Todo acto de comunicación es un acto de transmisión de información que en alguna medida está basada en una realidad más o menos externa al hablante o emisor. La realidad es en verdad una realidad percibida, por lo que cada receptor comparte una parte de la realidad y disiente en otra. Además, la parte de realidad que nuestros sentidos perciben se olvida con más facilidad si no se transmite, es decir, si ese receptor no la utiliza en calidad de emisor en un proceso de codificación. Esto se debe a que la comunicación de una realidad es una reelaboración de esa realidad, esto es, un acto de sentido por el que se materializan aquellas vagas sensaciones y percepciones primarias (Rodrigo Alsina, 2005). Por tanto, la gran transformación o elaboración subjetiva de la información es su paso de "realidad percibida" (o "realidad" a secas) a "realidad contada".

Sobre esta simple y asentada premisa filosófica, descansan algunas de las principales teorías que explican la lógica que rige la búsqueda, selección y tratamiento primario de la información. En primer lugar, los criterios por los que en general una información merece ser percibida y, sobre todo, merece ser contada son muy variados, pero en general, se sitúa a la novedad como criterio marco para la transmisión de la información. En la etimología de la palabra "news" en inglés, emerge el adjetivo definidor del concepto, escondido tras su homóloga "noticia" en español, pues no hace tanto a las noticias en español se les llamaba "nuevas". Igualmente, las "nuevas" o noticias también se venían a llamar "novelas", prueba de su conexión con el entretenimiento (Kishan Thussu, 2007).

A partir de ese criterio totalizador, la novedad, que comanda las motivaciones del acto comunicativo y predetermina la misma transmisión de la información, se derivan otros criterios que matizan estructural y formalmente la novedad como compendio de la intención del emisor y la atención del receptor en el discurso (Grosz y Sidner, 1986). El primero de estos criterios es la accesibilidad de la información. Todo hecho es considerado como informativamente relevante en función de qué información se dispone del mismo. Asimismo, en segundo lugar, la magnitud absoluta y relativa de la información del hecho es clave para realzar la información (cifras grandes, grandes personas o héroes, grandes cantidades de años...). En tercer lugar, existe una indudable jerarquía o agenda del emisor que condiciona esa formalización, pues cada hecho encaja mejor o peor en las estrategias del emisor (van Dijk, 1990). Y en cuarto lugar, la proximidad (geográfica y simbólica) del hecho informativo es también criterio para configurar la consideración de relevancia informativa de un hecho. 
Cuando se ha decidido que un hecho es relevante, su transmisión sólo es posible desde un determinado ángulo. Las teorías del framing y del priming postulan la imposibilidad de no tomar partido en la transmisión de la información de un hecho de la realidad (Jensen, 1998), pues de forma inevitable se estará proponiendo un ángulo desde el que mirarlo e interpretarlo. Existen seis ángulos fundamentales y primarios propuestos desde la teoría del periodismo: las 6 W's de Rudyard Kipling (qué, quién, dónde, cuándo, cómo y por qué), con dominancia del qué y el quien y subordinación estructural en forma de contextos temáticos múltiples del resto (Taboada y Mann, 2006). Este es además el nivel mínimo de manipulación o la ideología inevitable de todo discurso informativo: escoger un ángulo o una de las $6 \mathrm{~W}$ 's como núcleo informativo o rema del discurso (Valldubí y Vilkuna, 1998). Así, todo hecho puede ser mirado y relatado contextual y estructuralmente desde una vertiente política, económica, social...

Para entender el proceso por el que una información es más o menos fruto de un hecho de la realidad o deriva en mayor o menor medida de otra información, se aplica la teoría de los mediaevents y pseudoevents de Boorstin (1992) y los tipos de eventos definidos por Gomis (1991). Estos autores se dieron cuenta del protagonismo que tomaban los medios, pues sus teorías explican la forma en que los medios condicionan, modifican o crean la realidad (Tuchman, 1983); desde realidades modificadas por los medios (espectáculos musicales, deportivos, encuentro de políticos...), preparadas para los medios (apretones de mano, gestos, apariciones, etc.) o no-realidades creadas por y para los medios (ruedas de prensa). Los events, mediaevents y pseudoevents son bautizados por Gomis como eventos explosiones, apariciones, resultados y desplazamientos. Los eventos explosiones son el cero de intervención de los medios en el hecho, es decir, son los hechos de la realidad percibida o contada, pues una explosión (una dimisión, un terremoto, un atentado...) es conocida por el editor a través de notas de prensa, fuentes primarias diversas y fuentes secundarias. Las apariciones son el primer nivel de mediación, es decir, un primer nivel de mediaevents: aquellos hechos cuya naturaleza formal es modificada por la presencia de los ojos espectadores de los medios. Los resultados son el segundo nivel de mediación, pues los medios influyen directamente sobre las consecuencias de los hechos de la realidad. Y los desplazamientos son los pseudoevents de Boorstin, es decir, todos aquellos movimientos en pantalla que sólo se hacen porque precisamente hay una cámara que los graba. Siendo estos cuatro tipos de eventos diferentes niveles de mediación, todo evento será un "contar" de un "contar", y un contar de un contar de un contar, y así sucesivamente desde el primer nivel, las explosiones, hasta el último, los desplazamientos. Así, estos cuatro tipos de eventos son también grados de abstracción informativa y, por tanto, de capacidad manipulativa como segunda fuente de persuasión informativa.

Los entes de las informaciones sobre eventos de la realidad mantienen relaciones pragmáticas ("reales"), mientras que los entes de las informaciones sobre otras informaciones mantienen relaciones semánticas ("discursivas"). Por tanto, durante el proceso documentación y edición de las informaciones sobre un hecho que se quiere comunicar, el nivel de abstracción que se deriva del tipo de fuentes (eventos) de las que se parte está correlacionado inversamente con el nivel de credibilidad y por tanto de eficacia del acto comunicativo (Gans, 2004). 
Por último, la estructura formal del discurso informativo aplica unas claves dramáticas al género informativo (Puente, 1997). En primer lugar, el discurso informativo debe ser planteado como una trama entre personajes en un contexto espaciotemporal muy determinado. $\mathrm{Y}$ en segundo lugar, el emisor debe actuar como narrador implicado en el discurso informativo que está contando. Esta implicación debe derivarse del tipo de hecho como tal y no por estas claves dramáticas. Así, un dato cualquier podrá ser objetivamente positivo o negativo según la forma en que se haya obtenido: si proviene de un hecho de la realidad pragmática podrá ser considerado como positivo o negativo, pero si proviene de otra información semantizada se deberá mantener una distancia con el acto comunicativo. En caso contrario, aumentará las posibilidades de manipulación pero bajará la credibilidad y la eficacia del acto.

\section{La estructura textual del discurso informativo}

Una vez se dispone de la información necesaria sobre el pedazo de realidad que se pretende transmitir, el proceso se centra en la enunciación textual, esto es, la transformación de las informaciones en un texto lineal, mediante palabras, estructuras sintácticas y párrafos. La capacidad de "storytelling" o de construir un relato de las cosas es clave para poder conseguir los objetivos informativos, persuasivos y de entretenimiento de todo discurso (Ballenato, 2006). El arte de contar es tan antiguo como la humanidad, tan antiguo como el descubrimiento del fuego, alrededor del cual se desarrolló el lenguaje y la capacidad de contar historias correlacionada con la capacidad de atenderlas y comprehenderlas (van Dijk, 1999). El arte de contar es el arte de empatizar con el receptor. El cuentacuentos es aquel que conoce su audiencia y sabe estructurar y dosificar la información en un formato de relato ficcional en tres partes generales (Propp (1987):

1. Statu quo o situación estable inicial: aparecen los personajes en un contexto espaciotemporal, entre los que el héroe no es consciente de su condición y vive en sociedad y tranquilidad.

2. Se produce un cambio grande en la vida colectiva de la zona con gran perjuicio para civiles (víctimas o testigos), y el héroe se ve obligado a actuar; conoce al villano, sucumbe a él al tiempo que conoce un ayudante que mantiene la lucha.

3. El héroe persigue al villano en otro reino donde lo combate directamente y lo vence.

4. Compensación de parte de las anteriores víctimas o testigos de la gesta.

Esta estructura general proviene de la cultura oral pero se mantiene en la actualidad en el texto escrito. Siguiendo a Aristóteles (Barroso, 1992), este relato es antropocéntrico por naturaleza, pues la proyección y la identificación emocional con las personas es el mecanismo más poderoso para captar el máximo de atención de los receptores. Así, la personificación es el primer principio clave del relato. Los personajes de un relato se construyen en segundo lugar a través de la acción, que además hará avanzar la trama o conflicto. En tercer lugar, esa acción hace interactuar a los personajes, por lo que las relaciones entre ellos definen el avance de la narración. Y en cuarto lugar, estos personajes actúan y se relacionan en un espacio tiempo. 
Ahora bien, el discurso público formal asume estos principios y los adapta a su triple objetivo: entretenimiento al servicio de la persuasión, al servicio de la información. Así, en el discurso público se da por sabido en gran medida el estado normal del tema del que se hablará, por lo que el relato empieza con la gran novedad de la información (accesible, grande, con jerarquía y próxima). Una vez se ha presentado esa gran novedad o alteración del estado normal, se dará el contexto temático necesario para enmarcarla según orden de importancia, es decir, según una jerarquía descendente de contextos, representada por la clásica pirámide invertida (Fontcuberta, 1980). En este caso, esa jerarquía desciende hasta el nudo o narración de hechos descriptivos, momento en que se inicia una jerarquía ascendente o pirámide no invertida. Gradualmente, se recuperan los elementos temáticos en orden ascendente hasta el clímax final del discurso, es decir, un retorno a la novedad principal con la que se abría el discurso:

Gráfico 1. Teoría de la doble pirámide invertida. Fuente: creación propia

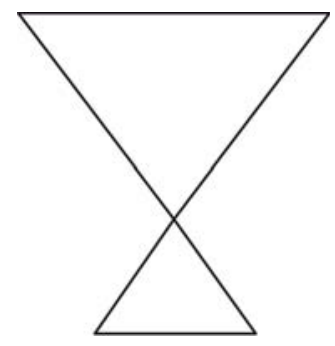

Por lo tanto, todo discurso se caracteriza por un inicio, un desarrollo y un final totalmente integrados (Wichmann, 2000; Mas Manchón, 2012b). Esa integralidad es fundamental para constituir una unidad indivisible y no totalmente comprendida hasta el final. Charaudeau define este tipo de "narratividad" como "le passage d'un état initial à un point d'arrivée, grâce à une transformation généralement réalisée sous forme d'épreuves" (2003: 40). El discurso informativo se compone de dos clímax, uno al principio y otro al final. Por obvio que pueda parecer, la marcación en todos los niveles de las fases del discurso, especialmente su inicio y final, es el rasgo más importante de la teoría narrativa, y serán las partes principales del moderno relato discursivo oral.

A partir de aquí, el orden en la presentación de la información sigue un triple criterio: el lógico (de importancia o primicia), el cronológico y el dramático o de entretenimiento. $\mathrm{Al}$ redactar un discurso informativo, generamos un texto en que, en primer lugar, se revela el desenlace de lo ocurrido (primicia) y, a continuación, se narran los detalles (cronológicamente) hasta un final con un nuevo desenlace (drama). Así, las frases gestionan y distribuyen fundamentalmente dos llamadas de atención a lo largo de un texto asimétrico, con una primera como protuberancia mayor, tal y como se ha visto en el esquema gráfico de la doble pirámide invertida. Hablamos pues de una mis en relief periódica y estructural (Charaudeau, 2003), centrada, principalmente, en unos elementos informativos siempre presentes y no únicamente temáticos. 
A partir de aquí, el texto debe tener una estructura sintáctica, léxica y semántica en el nivel de la frase. En general, el texto se compone de frases enunciativas cortas, simples y lógicas. La regla de oro para mantener la brevedad y la sencillez de la frase es el punto y la conjunción: siempre que al ir escribiendo sintamos que perdemos el hilo y que estamos añadiendo complejidad al texto (subordinación, conectores, explicaciones, alargamientos de la frase...), pongamos un punto y una conjunción alternativamente. De esta forma, proponemos utilizar una frase para cada hecho o idea. Esta estructura ideal se ve matizada por:

1. La coherencia global del texto entorno al núcleo: dando lugar a: a) frases más largas, con el objetivo de explicar en profundidad y detalle; b) frases aparentemente complicadas en busca de caminos para destacar el núcleo, y c) frases sintácticamente no convencionales pues no pocas veces convierten ese núcleo en falso sujeto activo de la acción.

2. La cohesión de las frases mediante un mínimo de redundancia en los conceptos abstractos y complejos. Se repiten por tanto estructuras sujeto-verbo-predicado y se introducen complementos (de lugar, tiempo, forma...) sucesivamente.

Según Martínez Albertos, "el periodista debe escribir no como quien escribe, sino como quien está hablando" (1998: 191). Por tanto, en primer lugar, el discurso informativo, al intentar imitar la naturaleza de la comunicación oral humana, pone en juego un estilo que bebe de forma primordial del estilo conversacional. El estilo de la conversación es directo y coloquial: "busca la expresión propia, teniendo en cuenta que la originalidad emana de la sinceridad con uno mismo y del acopio de belleza que vamos haciendo cada día, al ver, al leer y escribir buenas historias" (Bandrés et al., 2000: 222). Se podría decir que es formal en la forma macro del texto (su cohesión y coherencia) y coloquial en el contenido o microestructura (léxico y sintaxis).

En segundo lugar, la expresión conversacional debe tener fuerza, energía..., como cuando interpelamos a alguien para que nos escuche y entienda la dimensión de lo que estamos contando. Como decía George Bernard Shaw, citado por Bandrés et al. (2000: 222): "De Handel aprendí que el estilo consiste en la fuerza de la afirmación. Si puedes decir una cosa de un golpe, de forma incontestable, tienes estilo; si no, como mucho, eres un mercader del placer, un literato decorativo, un fabricante de música o un pintor de tres al cuarto. Handel, en cambio, tenía fuerza". En tercer lugar, debemos ser muy expresivos y huir de la monotonía (Merayo, 1998). El texto debe ser fresco, respirar cercanía y ausencia de complejos y ataduras. En suma, el estilo que se busca se mueve en una suerte de continuum entre dicotomías: informativo-interpretativo, objetivo-subjetivo, autoritario-testimonial, neutro-emocional, público-privado, narratológico-dramático, impersonal-personal, monológico-dialógico, universal-cercano, directo-continuo, inesperado-corriente.

A nivel de contenidos, debe destacarse el carácter novedoso o insólito de la información relevante con expresiones como: "Por primera vez en la historia...", "En cinco años...", etc. Asimismo, las cifras son siempre muy importantes, no tanto por su exactitud, sino por una correcta transmisión de su magnitud. Esto se hace mediante el uso de comparaciones, símiles o metáforas: más de 25.000 millones de euros, la mitad de los trabajadores, casi la totalidad de..., un iceberg del tamaño de Formentera, tres Ber- 
nabéus", etc. En este sentido, el dato deberá reflejar la idea que queremos transmitir: diremos que tal persona tiene 86 años y no que nació en 1927; a menos que el evento verse sobre el hecho de que creció en tiempos del crac económico previo a la Gran Guerra.

Naturalmente, el vocabulario dependerá también de un glosario de palabras-clave temáticas (Rodríguez Bravo y Mas Manchón, 2011), así como el uso de motes, apodos, explicaciones, o funciones para nombrar a determinadas personalidades. Por último, es importante ser muy preciso en el uso de las palabras, sobre todo el caso de los verbos de acción y los sustantivos. Se debe huir de palabras vacías como cosa, persona, o hacer/decir como verbos comodín. De hecho, se recomienda que ser muy precisos en la elección de las palabras que sirven al ángulo o enfoque de la información con el objetivo de evitar grandes manipulaciones y afectaciones de la credibilidad.

Finalmente, se dispondrá de un texto redactado y preparado para simular la espontaneidad discursiva.

\section{La estructural oral del discurso informativo}

El texto anterior es una partitura que debe ser interpretada vocalmente de la mejor de las formas gracias a las habilidades prácticas y al entrenamiento vocal del orador (Balsebre, 1994). Pero además, la propia estructura oral es un acto en sí mismo que puede dar valor suplementario al texto, pues no en vano aglutina toda la expresividad del proceso comunicativo. Intensidad, tono y tiempo son los tres rasgos vocales que debemos manejar para crear unas formas significativas que trasladen el contenido del mensaje:

"Una sucesión de tonos conforma la entonación, una sucesión y conjunción de tonos, duraciones e intensidades genera el acento y, por último, una secuencia de duraciones desarrolla el ritmo. [...]. Entonces, si capta la atención, la prosodia contribuye al mismo tiempo a la asimilación del contenido. En este caso, podemos pensar como una adecuada acentuación provoca un contraste acústico que dirige el interés del público hacia los datos más relevantes" (Rodero, 2003: 122).

En primer lugar, la intensidad es un parámetro que describe estímulos tan diferentes como un color, un sonido o una caricia. La intensidad precisa de un mecanismo articulatorio más sencillo, más primario, más rudimentario y más estable que el tono y el ritmo. De hecho, es, quizás, el parámetro prosódico que antes aprenden a manejar los bebes, el primero que manejaron los primeros homínidos y el que más usan los animales en general y los primates en particular. Por eso, la intensidad es la conductora de las emociones, como puede ser la rabia, la alegría, la tristeza, la indignación, la sobriedad, etc. Es de hecho el parámetro prosódico más natural y, por tanto, más difícil de manipular de forma consciente por parte del ser humano. Cuando mentimos, nuestra intensidad de habla nos delata.

La intensidad depende de la cantidad de aire en la articulación, por lo que se puede considerar como el combustible del habla. Por ello, se debe tener en cuenta el "trayecto" de habla al que se enfrenta el hablante para optimizar ese combustible, es decir, gastarlo allá donde sea necesario y llegar a los repostajes bastante vacíos pero sin apu- 
rar. No será lo mismo un viaje atravesando las largas llanuras de la estepa rusa que un viaje por las autopistas europeas. Un hecho de extraordinario impacto y muy urgente va a precisar la máxima exigencia de planificación energética de parte del enunciador, quien tendrá que planificar las respiraciones según el número y el orden de las ideas importantes que tiene que enunciar en cada frase, la presencia de grandes prominencias y su emplazamiento, la presencia de subordinadas, su entrenamiento y capacidad articulatoria (el cansancio que acumule o si esta resfriado), la complejidad de pronunciación de algunas palabras, etc.

La intensidad se genera o modifica de tres formas (Rodríguez Bravo, 2002):

1. el tratamiento fonético: depende del aparato fonador humano;

2. la posición locutor-micrófono: depende de la distancia física entre locutor y micrófono; $\mathrm{y}$

3. el tratamiento técnico: depende del grado de amplificación artificial con que es tratada la voz.

La intensidad depende del tipo de discurso, que puede ser público o social. La intensidad pública es aquella que se produce entre interlocutores a 1,5-3 metros de distancia, y que tienen una relación formal y esporádica, pero exenta de confianza. Se articularán intensidades medias, que no provocan ningún tipo de cansancio o esfuerzo en el emisor o en el receptor. Además, se debe provocar la sensación de que el presentador habla directamente a cada receptor, generando fidelidad y confianza. Por su parte, la intensidad social es aquella propia de la actitud de pregonar a públicos amplios (conferencia, clase o discurso político). El locutor debe tener una voz decidida, enérgica y tajante, y a la vez cálida y un tanto conmovedora.

La intensidad tiene tres funciones comunicológicas (Mas Manchón, 2011a). Primero, la intensidad marca las sílabas como pequeñas subidas y caídas de intensidad correspondidas con las articulaciones de diferentes fonemas. En segundo lugar, la "función afectiva" o "semántica de la intensidad" es la más reconocida por los expertos de locución y voz; por todos es sabido que una intensidad alta significa autoridad, rabia, agresividad, ánimo, grandes cifras o grandes personajes..., mientras que una intensidad baja comunica tranquilidad, intimidad, tristeza o cercanía (Rodríguez Bravo, 2002). Y en tercer lugar, a nivel pragmático, se utilizarán intensidades en aumento para significar incrementos del interés, de la densidad de información y de urgencia; y un descenso significaría ausencia de interés, escasez de información, confidencialidad... Una intensidad monótona supone neutralidad y objetividad. Si una proposición se quiere presentar como causa de la siguiente, se aumentará la intensidad de la primera y se disminuirá la de la segunda. Asimismo, los inicios siempre implican energía alta y los finales caídas de energía.

En segundo lugar, el tono es la vibración periódica de una onda compleja generada por un objeto al ser estimulado en un ambiente. El tono es sonoridad percibida las 24 horas del día y $\operatorname{los} 360^{\circ}$ a nuestro alrededor dentro de un radio determinado: el viento, el ladrido de un perro, el motor de una moto, etc. En todos estos casos, hay un objeto sonoro que vibra. Cuantas más vibraciones (hertzios) por unidad de tiempo, más alto o agudo será el tono. Estas vibraciones dependen de: 
1. la fuerza en que el objeto es estimulado,

2. el material del objeto

3. y su tamaño.

En el caso de las cuerdas vocales del ser humano, se habla de la fuerza articulatoria, y características y tamaño de estas cuerdas. Sólo algunos de esos tonos son intencionales y significativos, pocos están bien timbrados, y aún menos forman parte de una curva entonativa. Así, en el caso del habla, solo las vocales y algunas consonantes son sonoras. La entonación es intencional, continua y rítmica; por lo que es compleja y sólo el canto, la música y la voz la pueden generar. Por lo tanto, mientras tonos emitidos por cualquier tipo de fuente sonora invaden el día a día de las personas sin que éstas presten gran atención, la entonación es un fenómeno excepcional, complejo y con una gran carga significativa. Como resultado, se organiza la realidad sonora que nos envuelve en patrones melódicos: el canto de un pájaro, la melodía de un piano lejano, o la sirena de una ambulancia. No extraña, pues, que los humanos hayan sido capaces de inventar la música: se percibe música a nuestro alrededor. De todos los estímulos sonoros que nos rodean, la voz humana es el más rico. En teoría somos capaces de reconocer tantos timbres sonoros como personas en el mundo; en la práctica, una vida no es suficiente para llegar a escuchar a la mitad de los habitantes de la tierra.

Por tanto, resulta difícil hablar de tono sin hablar de entonación. Y cuando lo hacemos tenemos en mente una curva que suavemente sube, baja o se mantiene constante en función de las inflexiones de la voz. Efectivamente, definimos la entonación como la evolución del tono en el tiempo. Es, por tanto, una curva formada por datos de altura tonal en el tiempo. Navarro Tomas ya decía, en 1974, que toda curva melódica varía en función del acto comunicativo, es decir:

- la lógica del proceso: fruto de la intención del que habla;

- la emoción del emisor: afectividad con la que se habla;

- la entonación volitiva: expresión de un deseo en un contexto dado, y

- la entonación idiomática.

Se debe añadir el contenido del texto y el valor semántico y pragmático de cada palabra en el texto. Por tanto, la unidad mínima de la entonación es el énfasis de palabra, que se deberá realizar mediante picos tonales y como parte de una curva entonativa. Todas estas funciones se dan siempre de forma simultánea.

La tercera variable acústica es el tiempo. El tiempo está implícito cuando se habla de gestión y distribución de la intensidad y la entonación, pues la energía y el énfasis dependen de las pausas. Y los eventos tonales ocurren en el eje temporal según un determinado ritmo. La variable tiempo puede tener funciones muy diversas. Desde la sencilla separación de unidades mediante pausas más o menos largas, hasta el sentido de urgencia y relevancia de la información y el mantenimiento de una tensión narrativo-dramática mediante el ritmo (Fraisse, 1974).

Por una parte, las pausas del discurso pueden ser de 0,1 hasta 1 o 2 segundos de duración (Charaudeau, 1983: 43). Una pausa de 0,5 es considerada una pausa segmental que separa párrafos, y las pausas de 0.3 a 0,4 segundos de duración significan 
separación de unidades entonativas o grandes énfasis de la información, coincidente con respiraciones. Por debajo de 0,3 segundos se trata de pausas de énfasis o pequeñas respiraciones imperceptibles. Por otra parte, el ritmo es una actividad cognitiva que prevé el emplazamiento, el orden y la sincronización de los elementos rítmicos (Perona, 1992). La sílaba es el parámetro fundamental para generar el ritmo cadencial del habla y concentrar la sonoridad tonal para poder articular una entonación estilizada y melódica. A partir de una duración mínima, cada sílaba puede ser alargada para enfatizar la palabras en razón del objetivo comunicativo: la semántica (información alegre, triste, urgente, graciosa...) y el discurso (formal, informal, reverencial, solemne, espontáneo, didáctico, institucional, etc.) (Mas Manchón, 2012a).

\section{Modelo Estructural del Discurso Informativo}

Mediante las variaciones de intensidad, tono y ritmo, se genera la curva entonativa y las formas prosódicas. Por tanto, una forma prosódica es un conjunto de variaciones de intensidad, tono y tiempo con significación formal y textual según los niveles estructurales del modelo. Si el principal rasgo estructural del discurso público hablado es el énfasis, estas formas prosódicas vendrán definidas principalmente a partir de los tipos de acentos y su emplazamiento en la curva (Buff, 1985), pues el acento atrae la atención hacia la información nueva y más importante (Rodero, 2014; Mas Manchón, 2014b). Por tanto, en virtud de esta estructura multinivel, el acento actuará de palanca del resto de formas que configuran el discurso oral (De Ouden, 2004).

El discurso público se constituye de un estilo narratológico caracterizado por ritmos de variación (ritmo in crescendo y paradas súbitas), hasta una ralentización con parada final. Así, el acento en el discurso informativo oral estará mejor definido si:

1. coincide con una "palabra" cuyo referente es "clave" para el procesamiento de la información;

2. esa "palabras-clave" tiene muchas sílabas y es muy vocálica;

3. se inserta en frases cortas, directas y de orden lógico, separadas por pequeñas pausas de 0,2 segundos;

4. entre ideas comunicadas, separadas por pequeñas respiraciones superiores a 0,3 segundos, $\mathrm{y}$

5. produciendo unas inflexiones de tono e intensidad, y unas ralentizaciones del ritmo, coincidentes con las palabras-clave, periódicas durante la frase o idea, y entre pausas.

Se verán las diferentes formas prosódicas en función del tipo de unidad entonativas. La unidad entonativa es una serie de datos de pitch correspondidos con sílabas del discurso, estilizados en una curva continua a partir de puntos de inflexión máximos y mínimos organizados en grupos entre respiraciones. Por tanto, la unidad entonativa depende de:

- un contorno general;

- los niveles de los picos de acento;

- el timing de aparición de los niveles por sílabas;

- los niveles de variación entre niveles de pitch, y

- las keywords: énfasis macro melódico. 
No obstante, es difícil encontrar las divisiones naturales de la frase oral. Dice Gili Gaya (1950: 62, citado en Rodero, 2003: 126) que "ante una oración dada todos sentimos divisiones naturales y otras que nos parecerán absurdas". El tipo de frases que se utilizarán en el discurso determinarán un ritmo "segmental" muy importante, pues:

- Contribuye a una mejor comprensión del discurso.

- Ordena las respiraciones.

- Resalta la información nueva o noticiosa.

- Provoca "agradabilidad" y mantiene la atención.

$\mathrm{Si}$, por ejemplo, tenemos la siguiente frase: "El precio del compuesto acetilsalicílico ha bajado debido a la suspensión del gobierno del impuesto a las farmacéuticas", la intención del orador será diferente si se destaca las palabras "precio" y "bajado", las palabras "compuesto acetilsalicílico" o la palabra "gubernamental". Lo que sobre el papel es un simple énfasis de una palabra-clave se convierte en el momento de la oralización en un conjunto de formas prosódicas al servicio de un modelo global que reproduce y enriquece todos los rasgos formales y textuales aquí desarrollados (Mas Manchón, 2011b).

El modelo global del discurso público se organiza según tres tipos de unidades entonativas: de planteamiento, desarrollo y final (Mas Manchón, 2012b; Wichmann, 2000). En el comienzo de nuestro discurso se debe plantear el núcleo informacional por el que se justifica la intervención del orador. Por tanto, a nivel formal, se trata de una enunciación enfática del hecho relevante de la realidad, definido por un tipo de discurso, una información novedosa e importante y su correspondiente información temática que la enmarca. Por tanto, después de un inicio de marcación silábica muy enérgica, se presentan un mínimo de tres palabras-clave (de discurso, novedad y tema) (Hallyday, 1990) marcadas mediante picos tonales en orden descendente (forma downtrend) y hasta una primera respiración breve de un máximo de 0.3 segundos (pausa) e inicio de un nuevo downtrend mediante un pico reset.

A partir de este momento, se exponen los contextos temáticos de la información enmarcada por un jerarquía de las 6 w's como ángulos o perspectivas de esa información (Balsebre, 1994). Eso se traslada en forma de palabras temáticas en picos tonales bajos, pequeñas pausas y alargamientos de las sílabas tónicas, y pausas periódicas entre unidades entonativas. La tesitura (tono medio) es alta, pues se pretende mantener la atención con grandes picos tonales (prominencias) menos frecuentes y en las palabras clave de información nueva con cierta dosis de redundancia. El final de este fragmento es en forma de suspensión, pues enlaza con las zonas de tesitura baja del fragmento de desarrollo del discurso.

Un fragmento típico de desarrollo trata de narrar cronológicamente y con ciertas dosis de dramatismo (Puente, 1997) las acciones y relaciones de los personajes antes enunciados. Los verbos de acción presentan un ritmo cadencial medio con tesitura media-baja (en plateau) que pretende mantener la atención por su contenido, interrumpido por esporádicas prominencias o grandes énfasis (picos tonales y/o alargamiento silábicos y/o pausas antes o después de la palabra-clave). Esta dinámica narrativa de exposición de los detalles de la información en orden decreciente de im- 
portancia (vértice de la pirámide invertida) y con llamadas de atención eventuales avanza hacia un incremento de la relevancia informativa (pirámide no invertida) mediante prominencia en orden ascendente (uptrend) hacia un prominencia con reset (pausa de 0.3 segundos para tomar aire) y uptrends más marcados en el fragmento de final de discurso.

Por último, los fragmentos de inicio y desarrollo dan paso al fragmento de final, en el que el plateau con prominencias aisladas da paso a uptrends más marcados y constituidos de grandes prominencias en la información nueva, que vuelve a aparecer. El objetivo es mantener la atención con el desenlace del discurso, que, aunque es narratológico y basado en palabras de contenido de los hechos secundarios -por lo que el final no guarda simetría con el inicio, sí presenta grandes prominencias finales de la información relevante precedidas de grandes respiraciones (valles), pues la energía articulatoria se resiente a estas alturas del discurso. Hasta que una de esas grandes prominencias, la más grande de ellas, hace una violenta caída tonal y alargamiento silábico hasta el 0 de intensidad (coda).

Estos tres tipos de unidades definidas a partir de diferentes formas prosódicas dominan las fases del discurso oral sobre cualquier materia informativa con dosis del género persuasivo y el relato. Este modelo pretende hacer una gestión estratégica de la distribución del énfasis sobre la información oral (Rodero, 2013; Francuz, 2010) sin caer en los patrones rígidos y cantados de la locución clásica (de-la-Mota y Rodero, 2011). Por otra parte, se trata de un modelo de carácter general y flexible, por una parte, e integral y solidario, por otra. Por lo tanto, sus principios deben tomarse de forma orientativa, pero conscientes de la afectación que cada decisión del proceso implica sobre la eficacia comunicativa resultante.

\section{Conclusiones}

Este artículo ha tratado de aglutinar los conocimientos desarrollados en teorías del periodismo, modelos comunicativos y técnicas propias de la oratoria, la retórica o la lingüística al servicio de un modelo integral de expresión oral en público. Se ha tomado el discurso público como un acto de transmisión informativa en dónde la eficacia comunicativa depende en gran medida del resultado de someter los rasgos estructurales de la persuasión (o retórica) y el entretenimiento (o ficción narrada) a los objetivos de transmisión informativa sobre hechos de una realidad empírica o abstracta (mediática) y según unos rasgos acústicos y formales de la voz.

De esta forma, se han desarrollado las tres competencias básicas para la producción y realización de un discurso público, a través de los medios o en directo, y sobre cierta información compleja. Se trata de las competencias de gestionar y procesar cantidades ingentes de información, la competencia de sintetizarlas y simplificarlas en un texto oral, y la competencia de leer ese texto de forma espontánea y formal, eficaz y sencilla, comprensible... Por tanto, esos tres dominios competenciales son en realidad los tres niveles estructurales de este modelo integral.

Estas tres competencias son aplicadas diariamente en todo tipo de instituciones y empresas, por parte de cargos directivos, expertos externos o trabajadores. Se aplican de forma independiente o de forma conjunta, y por parte de una misma persona o 
como roles competenciales de diferentes profesionales. Esta perspectiva responde además a las necesidades de un mercado dinámico y promueve la transferencia de conocimiento de las teorías académicas a las prácticas profesionales. El trabajo en competencias básicas, específicas y transversales debe servir para reforzar la idea de un experto en comunicación que trascienda a la idea tradicional de periodista o publicista, y cuyo concepto ha entrado en crisis en los últimos años. En este sentido, este tipo de modelos teóricos integradores del campo de la comunicación deben tomar las riendas de la actividad investigadora en los diferentes géneros y formas de comunicación (interpersonales, grupales, públicas, "masivas"...) con el objetivo de proteger la especificidad de la disciplina y avanzar en su conocimiento científico (riguroso, metódico... y relevante, útil, público...). Esto sólo se consigue mediante explicaciones teóricas de cuyo conocimiento y práctica dependa la correcta realización de tareas valoradas económicamente, y cultural y socialmente.

Aunque indudablemente este modelo bebe directamente de la información mediática y del discurso informativo como género propio, lo cierto es que la unidad noticia representa el discurso de la eficacia en la transmisión de la información, por lo que actúa de patrón estructural de todo tipo de contenidos, sean documentos legales, civiles, sociales, culturales, políticos o industriales. La propuesta de aplicar un modelo que bebe de un género tan específico y trabajado como el periodístico a un conjunto de prácticas tradicionalmente separadas por la teoría, puede implicar cierto nivel de abstracción en lo que a todas luces pretende ser una propuesta aplicada. En este sentido, se espera que este modelo instituya nuevas líneas de investigación fruto de la confluencia de teorías desconectadas. Las líneas de futuro deben intentar aplicar los conceptos, teorías y técnicas de análisis aquí planteados a textos de temáticas específicas, para después someter su reelaboración textual a los principios propuestos y comprobar su realización efectiva y mejorada en el dominio oral. Si la marcación de las fases del discurso y de las categorías informativas responde a una estrategia integral del proceso productivo y receptivo, se podrá decir que el modelo está siendo aplicado. Por último, el ordenamiento y conexión de conceptos dispersos en modelos de orden superior puede contribuir a seguir estableciendo los límites y la especificidad de la comunicación.

\section{Referencias bibliográficas}

BALSEBRE TORROJA, Armand (1994): El lenguaje radiofónico. Madrid, Cátedra.

BALLENATO, Guillermo (2006): Hablar en público. Arte y técnica de la oratoria. Barcelona, Pirámide.

BANDRÉS, Elena; GARCÍA AVILÉS, José A.; PÉREZ, Gabriel; y PÉREZ, Javier (2000): El periodismo en la televisión digital. Barcelona, Paidós Comunicación.

BARROSO GARCÍA, Jaime (1992): Proceso de la información de actualidad en televisión. Madrid, Radiotelevisión Española.

BOORSTIN, Daniel J. (1992): The image: a guide to Pseudo-Events in America. New York, Vintage Books. [1961]. 
BLANCH, Margarida y LÁZARO, Paricia (2010): Aula de locución. Madrid, Cátedra.

CALHOUN, Sasha (2002): Using prosody in ASR: the segmentation of broadcast radio news. Master's thesis, University of Edinburgh.

CHARAUDEAU, Patrick (2003): El discurso de la información: la construcción del espejo social. Barcelona, Gedisa.

CHARAUDEAU, Patrick (1983): Langage et discours: éléments de sémiolinguistique: théorie et pratique. Paris, Hachette, cop.

BUFF, Robert (1985): La mise en relief acoustique dans le français radiophonique. Tesis doctoral en la Faculté des Lettres de l'Université de Zurich. ADAG. Administration et Druck, AG, Zurich.

DE-LA-MOTA, Carme y RODERO, Emma (2011): "La entonación en la información radiofónica". Anejo de Quaderns de Filologia. La Entonación hispánica, Facultat de Filologia, Traducció i Comunicació, Universitat de València.

DEN OUDEN, Hanny (2004): Prosodic realizations of text structure. University of Tilburg. Holanda.

FRAISSE, Paul (1967): Psychologie du temps. Paris, Presses Universitaires de France (PUF).

GROSZ, Barbara J. and SIDNER, Candance L. (1986): "Attention, intentions, and the structure of discourse". Computational Linguistics archive, vol. 12 (3), pp. 175204.

HALLIDAY, Michael Alexander Kirkwood (1990, 2. .a ed.): Spoken and written language. Oxford, Oxford University Press.

HUERTAS, Amparo y PERONA, Juan José (1999): Redacción y locución en medios audiovisuales: la radio. Barcelona, Bosch.

FONTCUBERTA, Maria (1980): Estructura de la noticia periodística. Barcelona, ATE.

FRANCUZ, Piotr (2010): "The impact of audio information intonation on understanding television news content". Psycology of Language and Communication, vol. 14 (1), pp. 71-86. DOI: 10.2478/v10057-010-0005-6.

JENSEN, Klaus Bruhn (ed., 1998): News of the world: world cultures look at television news. London, Routledge.

LANGER, John (2000): La televisión sensacionalista. El periodismo popular y las 'otras noticias'. Barcelona, Paidós Comunicación 112 debates.

MERAYO, Arturo (1998): Curso práctico de técnicas de comunicación oral. Madrid, Tecnos.

GANS, Herbert J. (2004): Deciding what's news. A study of CBS evening news, NBC nightly news, Newsweek, and Time. Evanston, Illinois, Northwestern University Press. 
GILI GAYA, Samuel (1956): "El ritmo en la poesía contemporánea”. Lecciones dictadas en la Cátedra Milà i Fontanals de la Universidad de Barcelona. Barcelona, Universidad de Barcelona.

GOMIS, Lorenzo (1991): Teoría del periodismo: cómo se forma el presente. Barcelona, Paidós.

MARTÍNEZ ALBERTOS, José Luis (1998): Curso General de redacción periodistica. Madrid, Paraninfo.

MARTÍNEZ, Fernando; SÁNCHEZ CABACO, Antonio; BADILLO, Antonio; y PARADISO, Juan Carlos (2000): Manual de prácticas de redacción periodística. La noticia. Salamanca, Publicaciones Universidad Pontificia de Salamanca.

MAS MANCHÓN, Lluís (2014a): Discurso informativo 2.0. Estructura formal, textual y oral de la noticia. Barcelona, UOC Oberta Publishing.

MAS MANCHÓN, Lluís (2014b): "Caracterización prosódica del foco de tema y rema en las noticias". Círculo de lingüística aplicada a la comunicación, núm. 59, p. 25. Madrid, Servicio de Publicaciones de la Universidad Complutense.

MAS MANCHÓN, Lluís (2012a): "Rhythm Structure in News Reading". Brazilian Journalism Research, num. 9, p. 2.

MAS MANCHÓN, Lluís (2012b): “Análisis Prosódico Discursivo de las Fases de la Noticia en Televisión”. Oralia, núm. 15, pp. 205-239.

MAS MANCHÓN, Lluís (2011a): "La intensidad en la noticia hablada en televisión". Estudios de fonética experimental, núm. 20, pp. 71-112.

MAS MANCHÓN, Lluís (2011b): "Modelo Superestructural de la Noticia en Televisión”. Estudios sobre el Mensaje Periodístico, vol. 17, núm. 1, pp. 95-116. Madrid, Servicio de Publicaciones de la Universidad Complutense.

MAS MANCHÓN, Lluís (2011c): "Estructura del discurso televisivo: hacia una teoría de los géneros". Cuadernos de información, núm. 29, pp. 77-90. DOI: 10.7764/cdi.29.238

NAVARRO TOMÁS, Tomás (1974): Manual de entonación española. (4. ${ }^{a}$ edición). Madrid, Guadarrama.

PERONA PÁEZ, Juan José (1992): El ritmo en la expresión radiofónica. Tesis doctoral. Bellaterra, Universidad Autónoma de Barcelona.

PUENTE, María Soledad (1997): Televisión: el drama hecho noticia. Chile, Universidad Católica de Chile.

PROPP, Vladímir (1987): Morfología del cuento. Madrid, Fundamentos.

RACHLIN, Allan (1988): News as hegemonic reality: American political culture and the framing of news accounts. New York, Praeger.

RODERO, Emma (2014): "The principle of distinctive and contrastive coherence of prosody in radio news: an analysis of perception and recognition". Journal of Nonverbal Behaviour. DOI: 10.1007/s10919-014-0201-5 
RODERO, Emma (2013): "Peculiar Styles when Narrating the News: The Intonation of Radio News Bulletins". Estudios sobre el Mensaje Periodístico, vol. 19, núm. 1, pp. 519532. Madrid, Servicio de Publicaciones de la Universidad Complutense.

RODERO ANTÓN, Emma (2003): Locución radiofónica. Madrid, Instituto Oficial de Radio y Televisión.

RODRIGO ALSINA, Miquel (2005): La construcción de la noticia. Barcelona, Paidós Comunicación.

RODRÍGUEZ BRAVO, Ángel y MAS MANCHÓN, Lluís (2011): "Inventario de palabras clave temáticas para la clasificación automática de noticias de televisión". Anales de documentación, vol. 14, p. 2. Ediciones de la Universidad de Murcia.

RODRÍGUEZ BRAVO, Ángel (2002): "Propuestas para una modelización del uso expresivo de la voz. Universidade de Tras-os-Montes, Alto Douro e Vila Real, 11, 69-92, Vila Real: Sector Editorial Serviços Gráficos da UTAD.

TABOADA, Maite, y MANN, William C. (2006): "Rhetorical Structure Theory: looking back and moving ahead". Discourse Studies, vol. 8, p. 423. DOI: $10.1177 / 1461445606061881$

TUBAU, Iván (1993): Periodismo oral. Hablar y escribir para radio y televisión. Barcelona, Paidós.

TUCHMAN, Gaye (1983): La Producción de la noticia: estudio sobre la construcción de la realidad. Barcelona, Gustavo Gili.

VALLDUBÍ, Enric y VILKUNA, Maria (1998): “On Rheme and kontrast. Syntax and" Semantics, vol. 29, pp.79-108.

VAN DIJK, Teun (1990): La noticia como discurso: comprensión, estructura y producción de la información. Barcelona, Paidós Comunicación.

KISHAN THUSSU, Daya (2007): News as entertainment. The rise of global infotainment. London, Sage Publications.

WICHMANN, Anne (2000): Intonation in text and discourse. Essex, Pearson Education.

Lluís Mas Manchón es profesor visitante en el Departamento de Comunicación de la Universidad Pompeu Fabra. 